\title{
O currículo de Pedagogia e a prática profissional: a concepção de bolsistas do Pibid
}

\section{The Pedagogy curriculum and the professional practice: the Pibid scholarship conceptions}

\section{El currículo de Pedagogía y la práctica profesional: la concepción de los becarios del Pibid}

\author{
Nonato Assis de Miranda ${ }^{1}$ \\ Ana Silvia Moço Aparício² \\ Paulo Sérgio Garcia
}

DOI: http://dx.doi.org/10.20435/serie-estudos.v22i46.1074

\begin{abstract}
Resumo: Esse texto apresenta os resultados de uma pesquisa de natureza qualitativa realizada com o objetivo de investigar as concepções de um grupo de estudantes de Pedagogia - bolsistas do Programa Institucional de Iniciação à Docência (Pibid) - acerca de uma possível relação entre o currículo de Pedagogia da universidade participante do Pibid e a prática profissional dos professores da educação básica parceira no projeto. Os dados foram obtidos por meio de entrevista semiestruturada realizada durante as reuniões semanais conduzidas pelo Coordenador Institucional do projeto. De posse das respostas, o material foi explorado, classificado, organizado e interpretado segundo técnicas provenientes da Análise de Conteúdo, atendendo, em todos os aspectos, os interesses investigativos da pesquisa. Os resultados mostram que as alunas participantes no Pibid entendem que existe uma relação muita próxima entre o currículo que é trabalhado pela universidade (curso de Pedagogia) no que tange aos aspectos didáticos e metodológicos e o currículo observado no cotidiano das escolas públicas participantes do Projeto.
\end{abstract}

Palavras-chave: educação básica; formação docente; Pibid.

Abstract: This text presents the results of a qualitative research carried out with the objective of investigating the conceptions of a group from Pedagogy students of Pibid about a possible relationship between the Pedagogy curriculum of the participating university in the Institutional Initiation Program for Teaching (Pibid) and professional practice of teachers of basic education partners in the project. The data were obtained through a semi-structured interview conducted during the weekly meetings sent by the Institutional Coordinator of the project. With the answers, the material was explored, classified, organized and interpreted according to techniques derived from Content Analysis, attending, in all aspects, the investigative interests of the research.

\footnotetext{
${ }^{1}$ Universidade Municipal de São Caetano do Sul (USCS); Universidade Paulista (UNIP), São Caetano do Sul, São Paulo, Brasil.

${ }^{2}$ Universidade Municipal de São Caetano do Sul (USCS), São Caetano do Sul, São Paulo, Brasil.
} 
The results show that the students participating in the Pibid understand that there is a very close relationship between the curriculum that is worked by the university Pedagogy course) regarding the didactic and methodological aspects and the curriculum observed in the daily life of the public schools participating in the Project.

Key words: basic education; teacher training; Pibid.

Resumen: Este texto presenta los resultados de una investigación de naturaleza cualitativa realizada con el objetivo de investigar las concepciones de un grupo de estudiantes de Pedagogía- becarios del Pibid-acerca de una posible relación entre el currículo de Pedagogía de la universidad participante del Programa Institucional de Iniciación a Docencia (Pibid) y la práctica profesional de los maestros de la educación básica asociada en el proyecto. Los datos fueron obtenidos por medio de una entrevista semiestructurada realizada durante las reuniones semanales encaminadas por el Coordinador Institucional del proyecto. En posesión de las respuestas, el material fue explorado, clasificado, organizado e interpretado según técnicas provenientes del Análisis de Contenido, atendiendo, en todos los aspectos, los intereses investigativos de la investigación. Los resultados muestran que las alumnas participantes en el Pibid entienden que existe una relación muy cercana entre el currículo que es trabajado por la universidad (curso de Pedagogía) en lo que se refiere a los aspectos didácticos y metodológicos y el currículo observado en el cotidiano de las escuelas públicas participantes del Proyecto.

Palabras clave: educación básica; formación docente; Pibid.

\section{INTRODUÇÃO}

Este texto apresenta os resultados de uma pesquisa realizada com um grupo de estudantes bolsistas do Programa Institucional de Iniciação a Docência (Pibid) de uma universidade de natureza privada, na cidade de São Paulo, implantado em uma Escola Municipal de Ensino Fundamental (anos iniciais) nesse mesmo município.

O Pibid, enquanto política pública de educação, é resultante de uma ação conjunta do Ministério da Educação, da Fundação Coordenação de Aperfeiçoamento de Pessoal de Nível Superior (Capes) e do Fundo Nacional de Desenvolvimento da Educação (FNDE), implantada com o propósito de fomentar programas de iniciação à docência de estudantes de instituições públicas e privadas ${ }^{3}$ de ensino superior no Brasil.

Com esse programa, o governo busca estimular a integração da educação superior com a educação básica por meio do estabelecimento de projetos de cooperação que melhorem a qualidade do ensino nas escolas da rede pública com a finalidade de elevar a qualidade das ações pedagógicas voltadas à formação inicial de professores nas licenciaturas das Instituições de Ensino Superior (GATTI, 2013-2014) e fomentar práticas docentes e experiências metodológicas de caráter inovador, bem

${ }^{3}$ O Edital Capes n. 62/2013 possibilitou que instituições de natureza privadas, também, fizessem a proposição de projetos de cooperação contemplando seus alunos e as escolas públicas de seu entorno. 
como tornar a escola pública um espaço de reflexão e crescimento na construção do conhecimento docente (RAUSCH; FRANTZ, 2013).

Dadas suas características e propósitos, esse programa é uma política pública que, embora não dê conta de resolver as fragilidades dos cursos de licenciatura do país, em certa medida, minimiza as críticas que a formação inicial docente tem recebido nos últimos anos que recaem, principalmente, sobre o currículo formal. Ocorre que não é de hoje que esse currículo tem se constituído em conteúdos e atividades práticas distanciadas da realidade escolar, numa perspectiva burocrática e cartorial não dando conta, portanto, de captar as contradições presentes na prática social de educar (PIMENTA, 1997) e, em razão disso, pouco contribui para gestar uma nova identidade do profissional docente (PICONEZ, 1991; PIMENTA, 1994). Isso ocorre, principalmente, porque ainda

[...] não contamos no Brasil, nas instituições de ensino superior, com uma faculdade, centro ou instituto que centralize a formação desses profissionais, de modo integrado, com perfil próprio, como observado em outras profissões (engenharia, medicina, direito, etc.) e, também, como ocorre em outros países, onde há unidades ou centros de formação de professores englobando todas as especialidades, com estudos, pesquisas e extensão relativos à educação, à atividade didática e às reflexões e teorias a ela associadas, nos diversos ramos do conhecimento. (GATTI, 2013-2014, p. 38-9).

Diante do exposto, supõe-se que, para alterar esse cenário, faz-se necessária uma força tarefa envolvendo governo em suas diferentes esferas, já que a formação docente precisa ser vista como política pública de Estado, e não apenas um esforço individual.

Destarte o Pibid não se constituir em uma política dessa natureza, principalmente pelo tratamento que o programa passou a ter a partir do segundo semestre de 2015 por parte do Governo Federal, ainda assim, ele pode representar uma alternativa ao problema aqui apresentado se houver vontade política no sentido de redirecionar sua trajetória e retomar os investimentos nos moldes anteriores porque esse é um programa que, até então, tem dado certo. Em razão disso, ele ganhou visibilidade, conforme informações sobre o tema encontradas em sítios, blogs, eventos, relatos, publicações de alunos, coordenadores e supervisores, com pesquisas e experiências realizadas sobre o Pibid nas diferentes universidades que participam do programa.

No que concerne à eficiência do Pibid, Gatti et al. (2014, p. 104) constataram, a partir de depoimento de bolsistas, que "a participação no Programa contribui para a permanência dos estudantes nas licenciaturas, para a redução da evasão e para atrair 
novos estudantes" (GATTI et al., 2014, p. 104). Quanto à aceitação, observa-se que "relatos dos alunos envolvidos são enfáticos ao reconhecerem o papel fundamental da vivência nas escolas para sua formação, principalmente pelo acompanhamento regular dos orientadores e supervisores" (MONTANDON, 2012, p. 53).

Ademais, a metodologia do Pibid atende aos anseios por uma formação docente menos teórica, na medida em que esse programa cria condições para que o estudante bolsista vivencie experiências em escolas de natureza pública, num processo de reflexão da prática, a fim de aprimorar sua formação, ao inserir-se no ambiente escolar. É oportuno mencionar, também que, chegando à escola, o estudante pibidiano "é iniciado nas tradições de uma comunidade de profissionais que exercem aquela prática e no mundo prático que eles habitam" (SCHÖN, 2000, p. 39).

Com isso, esse estudante pode se apropriar de "suas convenções, seus limites, suas linguagens e seus sistemas apreciativos, seu repertório de modelos, seu conhecimento sistemático e seus padrões para o processo de conhecer-na-ação" tendo em vista que esse programa oferece aos pibidianos "em equilíbrio, uma formação específica e pedagógica, aliada a vivências na educação básica que vai além da sala de aula" (ZAQUEU, 2014, p. 331). Por meio desse programa, as (os) bolsistas têm contato direto com alunos, professores, diretores, inspetores, além de participarem das reuniões de Jornada Especial Integral de Formação (JEIF) etc. nas escolas parceiras, como foi o caso desta pesquisa. Nessa perspectiva, o Pibid torna-se uma "ponte" entre a universidade e a escola contribuindo tanto com a formação de bolsistas quanto para a melhoria na qualidade de ensino da escola.

Isso posto, este trabalho tem o objetivo precípuo de analisar as concepções de um grupo de estudantes bolsistas do Pibid acerca das contribuições desse programa à formação docente. Para tanto, buscou resposta à seguinte indagação: como você percebe a relação entre o que é estudado no curso de Pedagogia e o que se observa na escola participante do Pibid no que concerne à atuação docente?

Considera-se que

[...] é expressiva a dimensão do PIBID como política pública vinculada à formação de professores no Brasil [...] na medida em que, dada a amplitude de projetos existentes, e da extensão territorial brasileira, é importante a realização de pesquisas em perspectivas macro e micro para avaliar de forma mais aprofundada os seus impactos para a aprendizagem da docência na formação, no contexto das IES, em diferentes regiões e estados. (PANIAGO; SARMENTO, 2017, p. 772-3). 
Supõe, portanto, que essa pesquisa vai ao encontro desse ponto de vista, pois analisa as concepções de estudantes participantes do Pibid acerca da formação docente na perspectiva curricular.

Para efeito didático, este artigo está, assim, organizado: além desta introdução e das considerações finais, inicialmente, empreendeu-se uma discussão acerca dos princípios, marcos regulatórios e das rupturas do Pibid. Em seguida, apresenta-se o método utilizado para realização da pesquisa, bem como as orientações para a análise dos dados. Por fim, são apresentados e analisados os dados da pesquisa o que inclui a categorização de respostas e a criação de categorias na perspectiva da análise de conteúdo.

\section{PROGRAMA INSTITUCIONAL DE INICIAÇÃO À DOCÊNCIA: PRINCÍPIOS, MARCOS REGULATÓRIOS E RUPTURAS}

O Programa Institucional de Iniciação à Docência (Pibid), criado em 2007, é uma ação de valorização dos futuros docentes durante seu processo de formação que é fundamentado nas Leis n. 9.394/1996 e n. 12.796/2013; na Portaria n. 96/2013 e no Decreto n. 7.219/2010.

Trata-se de uma iniciativa que "apoia projetos de iniciação à docência, elaborados e coordenados pelas Instituições de Educação Superior (IES), visando à meIhoria da formação oferecida pelos cursos de licenciatura, bem como da Educação Básica" (HARDOIM; CHAVES, 2014, p. 59). Portanto, em linhas gerais, o Pibid busca "fomentar a iniciação à docência, contribuindo para o aperfeiçoamento da qualidade da educação básica brasileira" (BRASIL, 2013, p. 2).

O Pibid faz parte de um conjunto de políticas públicas do Governo Federal voltadas para a formação inicial de professores com ênfase na valorização do magistério, elevação da qualidade e articulação da relação teórico-prática. Ademais, seus objetivos vão ao encontro das premissas defendidas tanto pelas Diretrizes Curriculares Nacionais (DCN) dos cursos de Licenciatura de 2002 que, segundo Costa (2012), dão importância à aprendizagem de procedimentos investigativos e de interpretação da realidade, no ambiente escolar, quanto às DCNs de 2015, que defendem como princípio da formação de profissionais da educação básica "a articulação entre a teoria e a prática no processo de formação docente, fundada no domínio dos conhecimentos científicos e didáticos, contemplando a indissociabilidade entre ensino, pesquisa e extensão" (BRASIL, 2015, p. 4). 
Por meio de projetos vinculados ao Pibid, propõe-se uma atuação coletiva dos futuros professores no espaço escolar, favorecendo trocas reflexivas acerca de suas práticas qualificando sua atuação e proporcionando-Ihes um processo contínuo de formação que se concretiza por meio da parceria existente entre universidade e escola pública. Diante disso, o Pibid constitui-se em uma política a partir da qual

[...] a formação docente inicial e continuada para a educação básica constitui processo dinâmico e complexo, direcionado à melhoria permanente da qualidade social da educação e à valorização profissional, devendo ser assumida em regime de colaboração pelos entes federados nos respectivos sistemas de ensino e desenvolvida pelas instituições de educação credenciadas. (BRASIL, 2015, p. 4).

Em razão disso, as propostas apresentadas pelas IES devem ser compatíveis com os propósitos definidos pela Capes para o programa, sendo que, dentre as exigências dessa agência de fomento, é imprescindível que as atividades do Pibid sejam cumpridas tanto em escolas com Índices de Desenvolvimento da Educação Básica (Ideb) abaixo da média da Região/Estado, quanto naquelas que tenham experiências bem sucedidas de trabalho pedagógico e de ensino-aprendizagem, de modo a apreender diferentes realidades e necessidades da educação básica e de contribuir para a elevação do Ideb, aproximando-o do patamar considerado no Plano de Metas Compromisso Todos pela Educação (CANAN; CORSETTI, 2014).

Iniciado em 2008, o Pibid teve um processo de expansão tamanho que, três após sua implantação, Gatti, Barreto e André (2011) apontavam que, apesar de ele encontrar-se em fase de implementação, cujos resultados obtidos, até então, não eram suficientes para avaliar sua eficácia, esse fato sinaliza, segundo essas mesmas autoras, um indicador de que esse programa representa uma política pública de formação docente que está dando certo.

Para ilustrar o exposto, empreendeu-se uma busca nos resultados dos editais Pibid/Capes, obtendo-se os seguintes números: no ano de 2009, foram selecionados projetos de 89 instituições federais e estaduais para o recebimento de bolsas e auxílios; em 2010, entraram no Programa mais 31 IES, comunitárias e municipais; em 2011, 104 instituições tiveram seus projetos habilitados no Pibid e, o edital n. 61/2013 selecionou 284 projetos de instituições públicas federais, estaduais e municipais bem como instituições filantrópicas, confessionais e privadas com e sem fins lucrativos.

Em 2014, nas suas diferentes modalidades, contava com um total de 313 projetos assim distribuídos: 26 na região Centro-Oeste do país; 66 na região Nordeste; 32 na 
região Norte; 117 no Sudeste e 72 na região Sul do Brasil. A iniciativa oferece um total de 90.254 bolsas, distribuídas entre licenciandos, professores supervisores, coordenadores de área de gestão, coordenadores de área e coordenação institucional. Com isso, o Pibid tornou-se o programa que mais cresceu na Capes ultrapassando, inclusive, o Programa Institucional de Iniciação Científica (PIBID), do CNPq (FALCÃO; FARIAS, 2017).

Diante do exposto, concorda-se com Gatti, Barreto e André (2011) que esse crescente número de instituições que submeteram suas propostas aos editais Pibid/ Capes revela, no mínimo, entusiasmo por essa política pública, considerando-se que as exigências são relativamente fortes.

Esse ponto de vista corroborou-se por meio de pesquisa recente realizada por Gatti et al. (2014, p. 107) apontando que, como política pública de educação, o Pibid "contribui para a valorização da profissão de professor; constitui-se em rara política de atenção à formação inicial dos professores para a educação básica; é um programa que desacomoda as licenciaturas e mobiliza escolas". E mais, "por suas contribuições, deve ser institucionalizada e tornada perene como política de Estado".

De fato, analisando-se a trajetória do Pibid de 2007 a 2014, não há como discordar do ponto de vista dessas pesquisadoras no que concerne ao papel desse programa enquanto política pública de educação, cuja tendência seria institucionalizar-se como política de Estado.

Entretanto, considerando-se os problemas enfrentados pelo programa, no segundo semestre de 2015, com o atraso no repasse de bolsas e a publicação da Portaria Capes n. 46 de 11 de abril de 2016, que revogava a Portaria Capes n. 96 de 18 de julho de 2013, considera-se que, além de o Pibid não se constituir em uma política de Estado, corria-se o risco de ele, até, mesmo ser descontinuado.

Essa portaria, além de redimensionar o número de bolsistas, basicamente extinguiu a figura do coordenador de área e tirou das instituições de educação superior (IES) a autonomia na elaboração do Projeto Institucional, por meio da definição de eixos estruturantes.

Ademais, ela limitava, no caso do curso de Pedagogia, a, no máximo, três bolsistas por escola, com o intuito de ampliar o número de escolas participantes do projeto que nem mesmo eram indicadas pela IES. Ao contrário, essas escolas foram, previamente, selecionadas pelo Governo por meio de uma lista com aquelas que obtiverem resultados insatisfatórios no Ideb, para que os projetos adaptados pelas IES pudessem atuar, de modo mais eficaz, na busca da melhoria da aprendizagem escolar em prol elevação de seus índices no ldeb. 
Com isso, essa nova orientação da Capes descaracterizava o objetivo precípuo do Pibid, que é a valorização dos futuros docentes durante seu processo de formação transformando-se em responsáveis pela recuperação das defasagens de aprendizagem de alunos das escolas participantes.

Outro agravante foi que, ainda em 2015, além do atraso no repasse de bolsas, a Capes impediu que as IES fizessem a substituição de bolsistas por meio do fechamento do sistema cuja abertura ocorreu, somente, após a publicação da Portaria n. 46/2016, mas com a condição de que o número de bolsistas não ultrapassasse o quantitativo de fevereiro de 2016 (Fórum Nacional dos Coordenadores Institucionais do Programa Institucional de Bolsas de Iniciação à Docência [FORPIBID] , 2016). Assim, a instituição que teve a maioria ou, até mesmo, a totalidade de seus bolsistas concluindo o curso em dezembro de $2015^{4}$ não conseguiu fazer as substituições em número suficiente para manter o projeto vigente em 2016, como foi o caso da universidade participante desta pesquisa, cujo projeto extinguiu-se em junho desse mesmo ano.

Não obstante, por pressão das universidades participantes do Pibid, mais precisamente pelos integrantes do Fórum Nacional de Coordenadores Institucionais do Pibid (ForPibid), a Portaria n. 46/2016 foi revogada por meio da Portaria n. 84 de 14/06/2016, prevalecendo a Portaria n. 96/2013, mas, desde então, não houve abertura de novos editais.

Diante do exposto, apesar de o Pibid, até então, ser considerado um programa que

[...]vem criando condições para um processo de formação consequente para o desenvolvimento profissional dos docentes de modo que possam participar do processo de emancipação das pessoas, o qual não pode ocorrer sem a apropriação dos conhecimentos. (GATTI et al., 2014, p. 107).

Sua permanência depende de vontade política, disponibilidade de recursos financeiros e o enfrentamento de forças opostas aos interesses de educadores e da sociedade, em termos mais abrangentes, que é a maior beneficiária dos investimentos na carreira docente.

\section{MÉTODO}

Para dar conta dos propósitos desta pesquisa, utilizou-se da abordagem qualitativa de pesquisa, isto é, aquela que intenciona conhecer e interpretar a realidade sem

\footnotetext{
${ }^{4}$ Nos termos da Portaria Capes n. 96/2016, o bolsista, ao concluir o curso, deve ser desligado do Pibid.
} 
nela interferir para modificá-la (CHURCHIL JR., 1987). Dessa forma, essa abordagem trouxe subsídios para interpretar informações peculiares provenientes de opiniões pessoais e subjetivas dos indivíduos envolvidos nesta pesquisa, ou seja, estudantes de Pedagogia participantes do Pibid.

Os dados foram obtidos durante as reuniões semanais orientadas pelo Coordenador Institucional, em especial, nas de final de semestre de 2015. De posse das respostas, o material foi explorado, classificado, organizado e interpretado segundo técnicas provenientes da Análise de Conteúdo, atendendo, em todos os aspectos, os interesses investigativos da pesquisa (BARDIN, 2016).

\section{ORIENTAÇÕES PARA ANÁLISE DOS DADOS}

Os questionários foram utilizados para investigar as percepções das estudantes acerca das contribuições do Pibid no processo de formação inicial docente. "A partir de então, todo o material reunido passou por um processo de análise e classificação de dados até a obtenção das variáveis" (VERASZTO et al., 2014, p. 75).

O trabalho foi organizado em três etapas, seguindo as orientações de Bardin (2016): a) pré-análise: organização do material constituído e uma leitura flutuante, para obter uma categorização dos dados obtidos; b) a exploração do material: a administração sistemática das decisões tomadas; c) tratamento dos resultados e interpretação: fase que combinou a reflexão, intuição e o embasamento nos dados empíricos para estabelecer relações buscando resultados a partir de dados brutos, de maneira a se tornarem significativos e válidos.

A partir desse processo, os dados passaram por codificação efetuada segundo regras precisas. Feito isso, os dados brutos deram lugar a categorias específicas criadas a partir das regras de contagem (BARDIN, 2016). Essa categorização diferenciou os dados reagrupando-os segundo preceitos embasados em referenciais teóricos.

Os dados permitiram criar cinco categorias de análise: Metodologia de Ensino; Tendência Pedagógica; Relação teórico-prática; Concepção Construtivista; Aderência Curricular que serão apresentadas na sequência.

\section{APRESENTAÇÃO E ANÁLISE DE DADOS: CATEGORIZAÇÃO DE RESPOSTAS}

Durante as reuniões de formação, as alunas bolsistas foram convidadas a opinar acerca de vários assuntos inerentes ao projeto Pibid tais como: motivos da escolha para participar do projeto; dificuldades enfrentadas no processo de implementação do projeto; argumentos a favor e contra o projeto; a relação existente entre o currí- 
culo trabalhado na universidade e a prática docente na escola de educação básica.

De posse das respostas, elegeu-se a última indagação como objeto de análise.

\section{CRIANDO CATEGORIAS}

Seguindo as orientações metodológicas apresentadas anteriormente, as respostas das bolsistas foram organizadas, classificadas e categorizadas considerando-se suas semelhanças. Os nomes atribuídos às categorias, bem como suas definições, foram escolhidos a partir da ideia central das respostas apresentadas e do referencial teórico adotado no trabalho (CANDAU, 2009; LIBÂNEO, 2006, 2002; LUCKESI, 2009; SOLÉ; COLL, 2009; PIAGET, 2000; SACRISTÁN, 2000; SILVA, 2003).

Destaca-se que, em virtude de algumas bolsistas terem apresentado opiniões variadas e, por vezes, contraditórias, elas podem ter sido classificadas em mais de uma categoria e, em razão disso, para a organização do trabalho, as respostas foram transcritas, e as bolsistas diferenciadas pelas letras iniciais de seus nomes.

\subsection{Categoria 1: Metodologia de Ensino}

Nessa categoria foram agrupadas as respostas inerentes aos saberes conceituais e metodológicos que trazem contribuições à atuação docente no ambiente escolar.

Ao estudar as metodologias de ensino, tais como Metodologia do Ensino de Língua Portuguesa, Metodologia do Ensino de Matemática e Ciências, por exemplo, essas podem ser entendidas como práticas pedagógicas operacionalizadas por meio de conjuntos de atividades propostas pelos professores com vistas a alcançar a aprendizagem de determinados conhecimentos, valores e comportamentos (TRAVERSINI; BALEM; COSTA, 2007).

Por outro lado,

O professor de qualquer disciplina, sendo um profissional do ensino, precisa conhecer e dominar conhecimentos e técnicas específicas da ação de ensinar. Se todo profissional do ensino necessita formação pedagógico-didática, com muito mais razão necessita dessa formação aquele professor de prática de ensino que forma outros professores. (LIBÂNEO, 2002, p. 89).

Nesses termos, considerando-se que, numa perspectiva simplista, a metodologia de ensino é o estudo das diferentes trajetórias traçadas e vivenciadas pelos educadores para orientar o processo de ensino e aprendizagem em função de certos objetivos ou fins educativos (formativos), intitulou-se essa categoria de metodologia cujas respostas apresentadas, a seguir, corroboram esse ponto de vista. 
A aluna KSF afirma (R1) "eu percebo que existe bastante relação, pois na faculdade estamos abordando muitas disciplinas de metodologia e conseguimos observar de perto como é o aprendizado das crianças, como é feito cada método e conseguimos perceber como é a realidade do ensino, a prática do que aprendemos" [sic].

Nessa mesma direção, outra bolsista tece o seguinte comentário: (R2) "as metodologias utilizadas em sala de aula correspondem ao que aprendemos em aula, mas deixa a desejar na utilização de instrumentos" (Aluna KRS).

Analisando-se o exposto, identificam-se aspectos inerentes tanto à dimensão técnica quanto à política e humana da prática pedagógica. Depreende-se, portanto, que "a prática pedagógica, exatamente por ser política, exige a competência técnica". Ademais, "as dimensões política, técnica e humana da prática pedagógica se exigem reciprocamente" (CANDAU, 2009, p. 23) apesar de supor que os alunos em formação ainda não têm condições de fazer essa análise.

\subsection{Categoria 2: Tendência Pedagógica}

Na perspectiva da tendência pedagógica tradicional, o papel da escola está, intimamente, ligado com a reprodução de conhecimentos. Esses, por sua vez, devem preparar o aluno para uma futura posição na sociedade (LIBÂNEO, 2006). A relação de aprendizagem entre professor e aluno acontece com muita autoridade, pois o professor, ocupando um lugar de destaque, no processo educativo, tem suas colocações tidas como únicas e verdadeiras.

Prestes a encerrar a segunda década do Século XXI, essa postura ainda é observada, conforme a fala desta aluna: (R3) "[...] a escola, em geral, busca novos rumos e trabalha de acordo com a proposta do PCNs e da Secretaria Municipal de Educação, porém, a grande maioria dos professores quando fecha a porta da sala, se comporta de maneira tradicional, com raras exceções, como é o caso da professora F. (Aluna MGG).

Observa-se, aqui, que a aluna reconhece a atuação de alguns professores da escola participante em uma perspectiva tradicional por perceber que algumas atividades são feitas individualmente sem a interação entre alunos e professores.

Supõe-se que, nesse caso, o professor limita-se apenas a transmitir o conhecimento, tornando-se, assim, a autoridade do saber, cuja postura também é reconhecida nesse depoimento: (R4) "tenho percebido, durante as observações referentes ao projeto, que o ensino tradicional não foi totalmente superado, portanto, esta tem sido a maior dificuldade das escolas atuais" (Aluna LOC). 
Para essa bolsista, o exercício da docência é um obstáculo ao processo de aprendizagem dos alunos tendo em vista que, apesar das críticas ao modelo, ainda existem professores que atuam a partir dos valores acumulados ao longo da história pelas gerações adultas. O depoimento apresentado, a seguir, também evidencia que a aluna reconhece tal aspecto: (R5) "isso me leva a refletir sobre as teorias que tenho estudado na faculdade; estas afirmam que o ensino tradicional só poderá ser superado quando a escola e os professores passarem a considerar o contexto político-social, cultural e econômico dos alunos ao fazer seu planejamento" (Aluna LOC).

De fato, isso pode ocorrer, contudo, o futuro professor precisa entender que [...] a sala de aula pode ser um espaço formador para o aluno. Espaço em que ele aprende a pensar, elaborar e expressar melhor suas ideias e a ressignificar suas concepções, ao ser introduzido no universo dos saberes teoricamente elaborados e nos procedimentos científicos de análise, interpretação e transformação da realidade. (GARRIDO, 2001, p. 125).

Em razão disso, concorda-se com Formosinho (2009, p.95), para quem "a formação de professores tem algumas especificidades em relação à formação de outros profissionais, mesmo em relação à formação de outros profissionais em serviço". Esse autor continua afirmando que "a docência é uma profissão que se aprende pela vivência da discência".

Portanto a concepção da aluna é prudente porque defende a necessidade de o professor planejar suas aulas sem perder de referência o contexto político-social no qual seus alunos se inserem. Contudo ela não pode esquecer que "a docência é uma profissão que se aprende desde que se entra na escola, pela observação do comportamento dos professores" (FORMOSINHO, 2009, p. 95) e, por esse motivo, ela, ao observar essa prática docente está aprendendo até mesmo a não fazer algo que, a seu ver, está em desacordo com suas concepções de docência.

\subsection{Categoria 3: Relação teoria-prática}

Sabe-se que o professor trabalha a dinâmica de aprender a teoria para compreender a prática e, ao mesmo tempo, para corrigi-la nos pontos deficientes e até para descobrir novas implicações para ela (CRUZ, 2014).

Na atuação docente, o professor, direta ou indiretamente, faz uso do referencial teórico de formação para sustentar sua prática. Essa ideia está presente no depoimento: (R6) "presenciamos continuamente as teorias aprendidas no curso, assim como acompanhamos o projeto desenvolvido pela professora F. E também pudemos, 
a partir das observações e vivências envolvidas (sic), criar projetos para as disciplinas que estávamos cursando no semestre" (Aluna BEG).

Sabe-se que educadores atuam e têm concepções diferentes acerca do mundo e da sociedade. Para Luckesi (2009), o educador é um sujeito que, conjuntamente a outros sujeitos, constrói, em seu agir, um projeto histórico de desenvolvimento do povo, que se traduz e se executa em um projeto pedagógico.

Nesses termos, a atuação do professor em sala de aula não é neutra, na medida em que sua ação pedagógica está intimamente relacionada com o tipo de homem que se pretende formar. A relação teoria-prática também percebida pelas alunas, como, por exemplo, nesta fala: (R7) "[...] na sala do 2ㅇ A em que ela é a professora polivalente, as práticas são mais abertas à participação dos alunos, existe compromisso com a formação social e cultural das crianças e o conteúdo é passado de maneira significativa" (Aluna MGG) tende a se materializar.

Assim, "as práticas vivenciadas no Pibid desde o início da formação, enseja aos formandos vivenciarem a relação teoria-prática de forma a concretizar a premissa 'A prática deverá estar presente desde o início do curso e permear toda a formação do professor', proposta no Artigo $12 \S 2$ ㅇ da Resolução brasileira do CNE/CP 1 (BRASIL, 2002 apud PANIAGO; SARMENTO, 2017, p. 777).

É oportuno mencionar que o modelo de agir da professora analisado pela aluna relaciona-se à concepção de Luckesi (2009, p. 28), para quem a "prática educacional não poderá ser, de forma alguma, uma prática burocrática". Ao contrário, "ela tem que ser uma ação comprometida ideológica e efetivamente".

Destaca-se, por fim, que a relação teoria-prática está presente na Resolução CNE/CP n. 2/2015.

Nessa resolução, entre outras questões, é apontada a necessidade dos cursos de formação de professores se voltarem mais para as questões da prática de ensino em sala de aula, e sinalizando que a formação dos professores para atuarem na Educação Básica deve ter uma base comum nacional, consubstanciada pela concepção de educação como processo emancipatório e pelo reconhecimento do trabalho docente na perspectiva da práxis. (PANIAGO; SARMENTO, 2017, p. 778).

Embora a matriz curricular da IES investigada não estivesse, à época dessa análise, adaptada a essa resolução, as manifestações das pibidianas sinalizam sobre a necessidade de aplicação da relação teoria-prática induzindo pensar que a formação docente, dentre outros aspectos, deve conduzir o futuro professor "à construção do 
conhecimento, valorizando a pesquisa e a extensão como princípios pedagógicos essenciais ao exercício e aprimoramento do profissional do magistério e ao aperfeiçoamento da prática educativa" (BRASIL, 2015, p. 24).

Ademais,

[...] considerando a identidade do profissional do magistério da educação básica proposta, deverá ser garantida, ao longo do processo, efetiva e concomitante relação entre teoria e prática, ambas fornecendo elementos básicos para o desenvolvimento dos conhecimentos e habilidades necessários à docência. (DOURADO, 2015, p. 309).

A relação teoria e prática deve estar presente não somente na matriz curricular nos termos da Resolução CNE n. 2/2015, mas também em projetos que estreitam a relação da formação inicial docente tal como enseja o Pibid.

Grosso modo, pode-se afirmar que o ideal para a formação inicial docente é o equilíbrio entre "o conhecimento teórico" que é "um elemento necessário para realizar uma boa prática profissional, com mais preparo para a resolução de problemas da área educacional" (HAAS; RIBEIRO, 2016, p. 43) e a prática docente que se dá tanto por meio de projetos como o Pibid quanto por atividades procedimentais de aula na perspectiva da Prática como Componente curricular (BRASIL, 2015).

Em síntese, o Projeto Pedagógico de Curso (PPC) das IES precisa ter claro que "deverá ser garantida, ao longo do processo, efetiva e concomitante relação entre teoria e prática, ambas fornecendo elementos básicos para o desenvolvimento dos conhecimentos e habilidades necessários à docência" (BRASIL, 2015, p. 11).

\subsection{Categoria 4: Concepção Construtivista}

A concepção construtivista trouxe, por meio de grandes repercussões, modificações às ideias, às práticas pedagógicas dos educadores e ao cotidiano escolar, tornando-se ao longo dos tempos o centro das atenções no âmbito educacional (CARRARO; ANDRADE, 2009).

Não obstante, "a concepção construtivista não é, em sentido estrito, uma teoria, mas um referencial explicativo que, partindo da consideração social e socializadora da educação escolar, integra contribuições diversas cujo denominador comum é constituído por um acordo em torno dos princípios construtivistas" (SOLÉ; COLL, 2006, p. 10).

Por outro lado, é inegável que, embora o construtivismo não seja um livro de receitas tal como afirmam esses autores, ao contrário, é um conjunto articulado de 
princípios a partir dos quais é possível diagnosticar, julgar e tomar decisões fundamentais inerentes ao ensino. A aluna KRA, por exemplo, percebe isso ao afirmar que (R8) "o conteúdo aprendido na faculdade é bastante utilizado no projeto, pois, com algumas alterações, a tendência (sic) pedagógica aplicada é a construtivista". E ainda acrescenta (a aluna) "Acredito ser a ideal, atualmente" [sic].

Apesar de a aluna confundir tendência pedagógica com concepção construtivista, depreende-se que ela analisa a ação da professora numa perspectiva que se opõe ao empirismo e inatismo considerando-se que o conhecimento não é dado, mas construído pelas ações do sujeito quando esse interage com os objetos (PIAGET, 2000).

Nesses termos, as bolsistas mostram-se muito entusiasmados por acreditar que a relação teórico-prática é uma realidade no cotidiano escolar. O depoimento da aluna CAR confirma esse ponto de vista (R9) "Eu fico encantada de ver, no trabalho da professora F. aquilo que estou aprendendo na faculdade; até mesmo o fato de poder (sic) comparar as diversas tendências existentes na escola já que temos contato com outros professores".

Essa bolsista vê a atuação da professora supervisora como exemplar considerando-se o que está estudando em sala de aula. Sua afirmação induz a pensar que sua supervisora tem uma atuação impecável cuja fundamentação teórica vai ao encontro das teorias pedagógicas de sua formação o que, por sua vez, diferencia-se de outros professores da mesma escola já que ela "tem contato com outros professores", o que Ihe dá o direito de fazer uma análise comparativa.

\subsection{Categoria 5: Aderência Curricular}

O currículo é um conceito de uso relativamente recente entre nós, se considerarmos a significação que tem, em outros contextos culturais e pedagógicos, nos quais existem pesquisas inerentes ao assunto (SACRISTÁN, 2000).

Quando se define o currículo de Pedagogia, sem perder de vista o contido nas Diretrizes Curriculares Nacionais (Resolução CNE/CP n. 1/2006), tem-se em mente que, a formação desse profissional precisa estar em consonância com o currículo da educação básica considerando-se que o ambiente escolar é, por excelência, o futuro local de trabalho do egresso desse curso. Espera-se, portanto, que o currículo das IES esteja em consonância com o trabalho realizado pelos professores da educação básica, conforme o observado por essa bolsistas: 
(R10) "[...] uma relação bem chegada (sic), pois a cada participação no projeto, na escola, vejo atividades parecidas com aulas que estamos tendo no curso de Pedagogia; é como se estivesse tendo uma ponte de raciocínio mutuo. Percebo que está tendo uma ligação (sic) bem trabalhada, os conteúdos são parecidos $e$, por vezes, os professores percebem e ficam felizes porque os conteúdos que estão sendo colocados (sic) em sala de aula nas escolas públicas são estudados na faculdade" (Aluna MFO).

Esse depoimento sinaliza que a aluna percebe que existe aderência entre o currículo da formação inicial docente (Pedagogia) e o currículo da escola investigada.

\section{CONSIDERAÇÕES FINAIS}

Esse trabalho foi realizado com a intenção de se verificar se as bolsistas do Pibid percebem relação entre o currículo de formação docente e o currículo da educação básica. Ou seja, buscou saber se o que o estudante aprende, na Universidade, efetivamente, contribui para sua futura atuação como docente.

A partir da análise dos discursos dos estudantes bolsistas do Pibid da IES investigada, foi possível verificar e confirmar a importância da iniciativa do programa em relação à formação de futuros Pedagogos. Grosso modo, pode-se afirmar que as condições do Pibid possibilitam a criação de um processo de formação contínua para o crescimento profissional dos docentes, quando eles passam a participar do processo de emancipação e desenvolvimento das pessoas como cidadãos (GATTI et al., 2014).

Analisando-se os depoimentos das alunas, observou-se que elas reconhecem a existência de uma relação muito estreita entre o que se aprende no curso de Pedagogia da instituição investigada e as metodologias de ensino adotadas pelas professoras nas escolas de educação básica participantes do projeto.

Os diferentes pontos de vista defendidos pelas bolsistas, em suas opiniões acerca das contribuições do Pibid à formação inicial docente, demonstram que as atividades desenvolvidas no projeto foram de grande valia à formação delas. Essa mesma análise evidenciou, também, que o Pibid atuou como um instrumento de reflexão, auxiliando-as em suas práticas pedagógicas e favorecendo a renovação de estratégias que poderão facilitar o processo de ensino aprendizagem de seus futuros alunos.

Destaca-se que "[...] na formação permanente dos professores, o momento fundamental é o da reflexão crítica sobre a prática. É pensando criticamente a prática de hoje ou de ontem que se pode melhorar a próxima prática" (FREIRE, 2011, p.40). 
Outro aspecto apontado pelas bolsistas, no que tange às contribuições do Pibid à formação inicial docente, foi a troca de experiência delas com o professor supervisor. Sobre esse assunto, entende-se que,

É na troca de experiências que os profissionais começam a reconhecer o que sabem e refletem sobre sua prática, de modo a ressignificar a sua maneira de pensar e agir na docência, proporcionando novas possibilidades de estarem resolvendo seus dilemas. O trabalho colaborativo proporciona a solidariedade, a troca de experiências e de valores, saberes que não podem ser desenvolvidos individualmente. (RAUSCH; FRANTZ, 2013, p. 637).

Em síntese, ficou evidente que a participação das bolsistas no Pibid conseguiu empreender nelas, uma visão mais próxima da realidade docente, do que é ser professor, situação esta que se presume não se evidenciar de forma satisfatória durante o cumprimento dos estágios supervisionados. Portanto os momentos proporcionados pelas universidades e as escolas parceiras foram fundamentais para que elas pudessem ter contato com o futuro campo de atuação profissional.

A despeito das vantagens apontadas nesta e em outras pesquisas, sabe-se que [...] os desafios encontrados na experiência docente farão parte da rotina do futuro professor, sendo que cada um deles deverá buscar a melhor solução, para que assim consigam melhorar as condições de ensino das escolas públicas, acreditando na possibilidade de mudança no cenário educacional e que o Pibid seja peça fundamental dessa conquista (PEREIRA; LIMA, 2016, p. 172).

Portanto, já que buscamos a melhoria da qualidade da educação, temos que investir na formação inicial e continuada docente, mas isso ocorrerá somente quando a educação for vista como prioridade nacional e como política pública de Estado, e não de governo como tem ocorrido nos últimos anos.

\section{REFERÊNCIAS}

BARDIN, L. Análise de conteúdo. Tradução de L. A. Reto e A. Pinheiro. 1. ed. 3. reimp. São Paulo: Edições 70, 2016.

BRASIL. Resolução CNE n. 2, de 1 de julho de 2015. Define as Diretrizes Curriculares Nacionais para a formação inicial em nível superior (cursos de licenciatura, cursos de formação pedagógica para graduados e cursos de segunda licenciatura) e para a formação continuada. Disponível em: <http://portal.mec.gov.br/index.php?option=com_docman\&view=download\&alias= 17719-res-cne-cp-002-03072015\&Itemid=30192>. Acesso em: 21 maio 2017.

. Lei n. 12.796, de 4 de abril de 2013. Altera a Lei no 9.394, de 20 de dezembro de 1996, que estabelece as diretrizes e bases da educação nacional, para dispor sobre a 
formação dos profissionais da educação e dar outras providências. Diário Oficial [da] República Federativa do Brasil, Brasília, DF, 5 abr. 2013. Disponível em: <http://www.planalto.gov.br/ ccivil_03/_ato2011-2014/2013/lei/l12796.htm>. Acesso em: 26 jan. 2017.

. Decreto n. 7.219, de 24 de junho de 2010, que dispõe sobre o Programa Institucional de Bolsa de Iniciação à Docência - PIBID e dá outras providências. Disponível em: <http:// www.planalto.gov.br/ccivil_03/_ato2007-2010/2010/decreto/d7219.htm>. Acesso em: 28 jan. 2017.

. Resolução CNE/CP n. 1, de 15 de maio de 2006 que institui Diretrizes Curriculares Nacionais para o Curso de Graduação em Pedagogia, licenciatura. Disponível em: < http:// portal.mec.gov.br/cne/arquivos/pdf/rcp01_06.pdf>. Acesso em: 22 dez. 2016.

. Lei n. 9.394, de 20 de dezembro de 1996. Estabelece as diretrizes e bases da educação nacional. Diário Oficial [da] República Federativa do Brasil, Brasília, DF, 23 dez. 1996. Disponível em: <http://www.planalto.gov.br/ccivil_03/leis/L9394.htm>. Acesso em: 26 jan. 2017.

CANAN, S. R.; CORSETTI, B. O professor em formação: o PIBID no contexto da política nacional de formação de professores. In: CONGRESSO IBERO-AMERICANO DE POLÍTICA E ADMINISTRAÇÃO DA EDUCAÇÃO, 4. Anais...Porto, Portugal: ANPAE, 2014.

CANDAU, V. M. (Org.).A didática em questão. 29. ed. Petrópolis, RJ: Vozes, 2009.

CARRARO, P. R.; ANDRADE, A. S. Concepções docentes sobre o construtivismo e sua implantação na rede estadual de ensino fundamental. Revista Semestral da Associação Brasileira de Psicologia Escolar e Educacional(ABRAPEE), São Paulo, v. 13, n. 2, p. 261-8, jul./dez. 2009.

CHURCHILL JR., G. A. Marketing research: methodological foundations. Chicago: The Dryden Press, 1987.

COORDENAÇÃO DE APERFEIÇOAMENTO DE PESSOAL DE NÍVEL SUPERIOR (CAPES). Portaria n. 46, de 11 de abril de 2016. Aprova o Regulamento do Programa Institucional de Bolsa de Iniciação à Docência - Pibid. Disponível em: <http://www.capes.gov.br/images/stories/ download/legislacao/15042016-Portaria-46-Regulamento-PIBID-completa.pdf>. Acesso em: 28 jan. 2017.

. Portaria n. 84, de 14 de junho de 2016. Disponível em: <http://www.capes.gov.br/ images/stories/download/legislacao/15062016-Revogacao-da-Portaria-n-46-2016.pdf>. Acesso em: 28 jan. 2017.

Portaria n. 96, de 18 julho de 2013. Disponível em: <https://www.capes.gov.br/ images/stories/download/legislacao/Portaria_096_18jul13_AprovaRegulamentoPIBID.pdf>. Acesso em: 28 jan. 2017.

COORDENAÇÃO DE APERFEIÇOAMENTO DE PESSOAL DE NÍVELSUPERIOR (CAPES); PROGRAMA INSTITUCIONAL DE BOLSAS DE INICIAÇÃO À DOCÊNCIA (PIBID). Edital 61/2013. Disponível em:<https://www.capes.gov.br/images/stories/download/editais/Edital_061_2013_PIBID. pdf>. Acesso em: 18 dez. 2016. 
COSTA, F. F. Formação inicial de professores: novas políticas para velhas práticas. In: SEMINÁRIO DE PESQUISA DA REGIÃO SUL, 9., 2012. Anais...Caxias do Sul, RS: UCS, 2012. Disponível em: <http://www.ucs.br/etc/conferencias/index.php/anpedsul/9anpedsul/paper/ viewFile/2021/466>.

CRUZ, S. A. B. Formação Continuada à luz de Meireu. Curitiba, PR: Appris, 2014.

DOURADO, L. F. Diretrizes curriculares nacionais para a formação inicial e continuada dos profissionais do magistério da educação básica: concepções e desafios. Educação \& Sociedade, Campinas, SP, v. 36, n. 131, p. 299-324, abr./jun. 2015.

FALCÃO, G. M. B.; FARIAS, I. M. S. Formação de professores e o Programa Institucional de Bolsa de Iniciação à Docência (PIBID): apontamentos sobre avanços e contradições de um programa. Série-Estudos, Campo Grande, MS, v. 22, n. 44, p. 161-79, jan./abr. 2017.

FORMOSINHO, J. Formação de professores: aprendizagem profissional e acção docente. Porto, Portugal: Porto Editora, 2009.

FÓRUM NACIONAL DOS COORDENADORES INSTITUCIONAIS DO PROGRAMA INSTITUCIONAL DE BOLSAS DE INICIAÇÃO À DOCÊNCIA (FORPIBID). Informe ForPibid n. 07/2016 avanços e desafios para o Pibid. Disponível em: <http://www.forpibid.net.br/informes/informe_ forpibid_072016.pdf>. Acesso em: 27 jan. 2017.

FREIRE, P. Pedagogia da autonomia. 43. ed. São Paulo: Paz e Terra, 2011.

GARRIDO, E. Sala de aula: espaço de construção do conhecimento para o aluno e de pesquisa e desenvolvimento profissional para o professor. In: CASTRO, A. D.; CARVALHO, A. M. P. (Org.). Ensinar a ensinar: didática para a escola fundamental e média. São Paulo: Cengage Learning, 2001. p. 125-41.

GATTI, B. A.; BARRETTO, E. S. S.; ANDRÉ, M. E. D. A. Políticas docentes: um estado da arte. Brasília: Unesco, 2011.

GATTI, B. A. et al.Um estudo avaliativo do Programa Institucional de Bolsa de Iniciação à Docência (Pibid). Textos FCC, São Paulo, v. 14, p. 1-120, set. 2014. Disponível em: <https:// www.capes.gov.br/images/stories/download/bolsas/24112014-pibid-arquivoAnexado.pdf>. Acesso em: 29 jan. 2017.

GATTI, B. A. A formação inicial de professores para a educação básica: as licenciaturas. Revista USP, São Paulo, n. 100, p. 33-46, dez./jan./fev. 2013-2014.

HARDOIM, R. L. A.; CHAVES, I. M. A. B. O Pibidem narrativas e a formação de professores. In: FLORES, M. A.; COUTINHO, C. (Org.). Formação e trabalho docente: tendências e desafios atuais. Santo Tirso, Portugal: De Facto Editores, 2014. p. 57-69.

HAAS, C. M.; RIBEIRO, E. F. D. "Ser pedagogo" para alunos egressos de um curso de pedagogia: dialogando com a prática formativa. Revista de Estudos Aplicados em Educação, São Caetano do Sul, SP, v. 1, n. 1, p. 30-48, jan./abr. 2016.

LIBÂNEO, J. C. Democratização da Escola Pública: a pedagogia crítico-social dos conteúdos. 21. ed. São Paulo: Loyola, 2006. 
Didática: velhos e novos temas. Goiânia: Edição do Autor, 2002.

LUCKESI, C. C. O papel da didática na formação do educador. In: CANDAU, V. M. (Org.).A didática em questão. 29. ed. Petrópolis, RJ: Vozes, 2009. p. 25-34.

MONTANDON, M. I. Políticas públicas para a formação de professores no Brasil: os programas Pibid e Prodocência. Revista da ABEM, Londrina, PR, v. 20, n. 28, p. 47-60, 2012.

PANIAGO, R. N.; SARMENO, T. A formação na e para a pesquisa no PIBID: possibilidades e fragilidades. Educação \& Realidade, Porto Alegre, RS, v. 42, n. 2, p. 771-92, abr./jun. 2017.

PEREIRA, A. K.; LIMA, G. G. O Pibid na formação dos licenciandos em química do IFTM campus Uberaba: (re)pensando a docência na educação básica. HOLOS, ano 32, v. 3, p. 150-73, 2016.

PICONEZ, S. A prática de ensino e o estágio supervisionado. Campinas, SP: Papirus, 1991.

PIMENTA, S. G. O estágio na formação de professores-unidade teoria e prática? São Paulo: Cortez, 1994.

. Formação de professores: saberes da docência e identidade do professor. Nuances Estudos sobre Educação, São Paulo, SP, v. 3, n. 3, p. 5-14, 1977.

PIAGET, J. Biologia e conhecimento: ensaio sobre as relações entre as relações orgânicas e os processos cognoscitivos. 3. ed. Petrópolis, RJ: Vozes, 2000.

RAUSCH, R. B; FRANTZ, M. J. Contribuições do PIBID à formação inicial de professores na compreensão de licenciandos bolsistas. Atos de Pesquisa em Educação, Blumenau, SC, v. 8, n. 2, p. 620-41, maio/ago. 2013.

SACRISTÁN, J. G. O currículo: uma reflexão sobre a prática. 3. ed. Porto Alegre: Artmed, 2000.

SCHÖN, D. A. Educando o profissional reflexivo: um novo design para o ensino e a aprendizagem. Tradução de Roberto Cataldo Costa. Porto Alegre: Artes Médicas Sul, 2000.

SILVA, T. T. Documentos de identidade: uma introdução às teorias do currículo. 2. ed. Belo Horizonte: Autêntica, 2003.

SOLÉ, I.; COLL, C. Os professores e a concepção construtivista. In: COLL, César et al. O construtivismo na sala de aula. 6. ed. São Paulo: Ática, 2006. p. 9-28.

TRAVERSINI, C. S.; BALEM, N; COSTA, Z. Que discursos pedagógicos escolares são validados por professores ao tratar de metodologias de ensino? In: CONGRESSO INTERNACIONAL DE EDUCAÇÃO: PEDAGOGIAS (ENTRE) LUGARES E SABERES, 5, 20-22 ago. 2007. Anais... São Leopoldo: UNISINOS, 2007. CDROM.

VERASZTO, E. V.; CAMARGO, E. P.; MIRANDA. N. A.; CAMARGO, J. T. F. Professores em formação em ciências da natureza: um estudo acerca da atuação de cegos congênitos em atividades científicas. Formação Docente, Belo Horizonte, v. 6, n. 10, p. 69-86, jan./jun. 2014.

ZAQUEU, A. C. M. Pibid: política educacional ou medida Emergencial? RG\&PP, v. 4, n. 2, p. 324-33, 2014. 


\section{Sobre os autores:}

Nonato Assis de Miranda: Doutor em Educação pela Universidade Estadual de Campinas, Coordenador do Programa de Pós-Graduação em Educação- Mestrado Profissional em Educação da Universidade Municipal de São Caetano do Sul e Coordenador Geral do Curso de Pedagogia da Universidade Paulista. E-mail: mirandanonato@uscs.edu.br

Ana Silvia Moço Aparício: Doutorado em Linguística Aplicada pela Universidade Estadual de Campinas (UNICAMP), com estágio sanduíche em Didática de Língua Materna no LIDILEM (Laboratoire de Linguistique et Didactique des Langues Etrangères et Maternelle) de I'Université Stendhal Grenoble 3, na França, e pós-doutorado em Educação pela Fundação Carlos Chagas. Vice Coordenadora do Programa de Pós-Graduação em Educação- Mestrado Profissional em Educação da Universidade Municipal de São Caetano do Sul. E-mail: anaparicio@uol.com.br

Paulo Sérgio Garcia: Doutor em Educação pela Faculdade de Educação da Universidade de São Paulo e Pós-doutorado na Feusp. Professor do Mestrado Profissional em Educação da Universidade de São Caetano do Sul (USCS) e Coordenador do Projeto de observatório da Região do Grande ABC. E-mail: garciaps@usp.br

\section{Recebido em junho de 2017}

Aprovado para publicação em setembro de 2017 
